Int. J. Electrochem. Sci., 15 (2020) 12504 - 12523

International Journal of

ELECTROCHEMICAL

SCIENCE

www.electrochemsci.org

\title{
Five-axis Numerical Control of Electrochemical Mechanical Polishing of an Integral Impeller
}

\author{
Bo Xu ${ }^{1,2, *}$, Weimin Gan ${ }^{1,2}$, Yafeng He ${ }^{1,2}$, Xiangzhi Wang ${ }^{1,2}$, Feihong Yin $^{1}$, , Xin Wang ${ }^{2}$ \\ ${ }^{1}$ School of Aeronautics and Mechanical Engineering, Changzhou institute of Technology, Changzhou \\ 213002, P.R. China \\ ${ }^{2}$ Key Laboratory of Special Procegesand of Colleges and University of Jiangsu Province, Changzhou \\ 213002, P.R. China \\ ${ }^{3}$ School of Mechanical Engineering, Changzhou University, Changzhou 213164, P.R. China \\ *E-mail: xubo125@163.com
}

doi: $10.20964 / 2020.12 .80$

Received: 30 July 2020 / Accepted: 19 September 2020 / Published: 31 October 2020

The blade surface morphology has a significant impact on the life, performance, and stability of aeroengine integral impellers. The surface roughness of such free-form surfaces can be reduced using numerical control electrochemical mechanical polishing (NC ECMP), which is a combination of CNC technology, electrolytic polishing, and mechanical grinding. In this study, based on a YG8 cemented carbide specimen, two types of cathode polishing plate materials were compared and selected. The electrolyte ratio was optimized by conducting an orthogonal test. The relationship between the voltage, feed speed, spindle speed, duty cycle, cathode positive pressure, and surface roughness were studied. Finally, an integral impeller was polished under a set of optimized parameters, and its surface roughness was reduced from $\mathrm{Ra} 0.85 \mu \mathrm{m}$ to $\mathrm{Ra} 0.215 \mu \mathrm{m}$. Our results confirm that the five-axis NC ECMP is an economical and effective method for polishing complex surfaces, particularly in aerospace applications.

Keywords: Integral Impeller; Cemented Carbide; NC Electrochemical Mechanical Polishing; Surface Morphology

\section{$\underline{\text { FULL TEXT }}$}

(C) 2020 The Authors. Published by ESG (www.electrochemsci.org). This article is an open access article distributed under the terms and conditions of the Creative Commons Attribution license (http://creativecommons.org/licenses/by/4.0/). 